\title{
Type D personality impairs Quality of Life, coping and short-term psychological outcome in patients attending an outpatient intensive program of cardiac rehabilitation
}

\section{La personalità di Tipo D peggiora la qualità di vita, il coping ed il profilo psicologico a breve termine in pazienti che svolgono un programma ambulatoriale intensivo di Riabilitazione Cardiologica}

\author{
Elena Sogaro1, Francesca Schininà1, Costanza Burgisser2, Francesco Orso2, \\ Rachele Pallante ${ }^{2}$, Teresa Aloi ${ }^{3}$, Duccio Vanni ${ }^{1}$, Adolfo Pazzagli1, Francesco Fattirolli2
}

\begin{abstract}
Type D personality impairs Quality of Life, coping and short-term psychological outcome in patients attending an outpatient intensive program of cardiac rehabilitation. E. Sogaro, F. Schininà, C. Burgisser, F. Orso, R. Pallante, T. Aloi, D. Vanni, A. Pazzagli, F. Fattirolli.

Background: Type D personality represents a risk factor for adverse outcome and impaired Quality of Life (QoL) in CHD patients. Only few studies investigated Type D patients following cardiac rehabilitation (CR). No study investigated Type $D$ personality in Italian patients attending a CR program of 4 weeks. The aims of the study were a) to verify the presence of Type $D$ personality among patients attending an Italian CR program; b) to investigate psychological health status, QoL and coping style of CR patients and c) to test the influence of Type $D$ personality on CR patients outcome.

Methods: Data from 59 patients attending an outpatient intensive program of 4 weeks of $C R$ were collected at admission, and 1 month after discharge, using a set of self-report questionnaires. Variables were measured using CBAH, DS-14, Q-LES-Q and Brief COPE Scale.

Results: The percentage of Type $D$ personality found in the study sample was $39 \%$. At admission Type D patients showed a significant lower level of psychological health status and QoL satisfaction compared to non Type D patients $(p<0.05)$. After CR a significant percentage of Type D pa-
\end{abstract}

tients, despite an overall improvement, continued to show a clinically relevant psychological impairment in terms of anxiety $(p=0.003)$, depressive $\operatorname{mood}(p=0.001)$, impairment in psychophysical well-being $(p=0.002)$, perceived psychophysical stress $(p=0.002)$, interpersonal difficulties $(p<0.001)$, and social anxiety $(p=0.045)$. Type D personality was also found to be associated with a significant greater use of maladaptive coping strategies $(p<0.05)$.

Conclusions: Type D personality played a significant clinically relevant role on psychological health outcome in CR. Type D personality patients reported a significant higher level of psychological impairment, in terms of anxiety, depressive mood, impairment in psychophysical wellbeing, perceived psychophysical stress, interpersonal difficulties, social anxiety, and a significant lower QoL, prior and after CR. Type D personality seemed also to be associated with maladaptive coping strategies. Importance of assessment for Type D personality is warranted in CR setting, as additional interventions seem required to enhance the outcome of these patients defined in letterature at high-risk.

Key words: Cardiac rehabilitation; Coronary heart disease; Psychological health; Quality of Life; Type D personality; coping style.

Monaldi Arch Chest Dis 2010; 74: 181-191.

Department of Neurological and Psychiatric Sciences (1), Department of Critical Care Medicine and Surgery, Cardiac Rehabilitation Unit (2), Department of Neurological and Psychiatric Sciences, Clinical Psychology Unit (3), University of Florence and Azienda Ospedaliero Universitaria Careggi, Florence, Italy.

Corresponding author: Elena Sogaro; Department of Neurological and Psychiatric Sciences, University of Florence, Azienda Ospedaliero Universitaria Careggi, Viale Morgagni, 85; I-50134 Firenze, Italy; Phone number: $+39055429841 ;$ Fax number: +39 055 4298424; E-mail address: elesogar@tin.it

\section{Introduction}

Several studies have shown that prognosis of Coronary Heart Disease (CHD) is negatively influenced by psychological and psychosocial factors [13]. In recent years a series of studies conducted by Denollet et al. $[4,5]$ have shown Type D personality to be a 'distressed personality' profile leading to increased vulnerability for emotional, social difficulties and psychological risk factor [5-11]. Type D personality construct refers to individuals who simultaneously experience high level of negative affectivity and high levels of social inhibition [12]. Patients with Type D personality tend to experience increased levels of anxiety, irritation, and depressed mood across situations and time, while not sharing these emotions in social interactions because of fear of rejection or disapproval by others [13].

Type D personality also represents a psychosocial risk factor for a wide range of adverse health 
outcome including morbidity, mortality, poor prognosis and impaired Quality of Life across different cardiovascular patient groups, independent of standard cardiac risk factors, as Denollet et al. studies $[11,14]$ have repeatedly demonstrated.

Identification of cardiac patients at risk for adverse health outcome has become a priority, and modification of this risk comprises the fundamental objective of primary and secondary interventions.

Cardiac Rehabilitation (CR) programs are proven treatments for individuals with CHD, resulting in improved health status, reduced morbidity and mortality, compared with usual care [1518]. In addiction, CR including all core components of cardiac rehabilitation are effective in reducing emotional distress $[19,20]$. Nevertheless, to our knowledge, only few studies [5,21,22] examined the effect of CR on Type D personality. No study investigated Type D personality in an Italian CR program of 4 weeks. One study found a beneficial effect of rehabilitation on mood in Type D patients [5], a second study observed a reduction of Type D score, anxiety and depressive symptoms following expanded CR [21]. The last study revealed a poorer health status reported by Type D patients compared with non Type D, together with a relevant and stable effect of Type D personality on CR outcome [22].

The purposes of the present study were: 1) verifying the presence of Type D personality among patients attending an Italian CR program 2) investigating psychological health status (anxiety, depressive mood, psychophysical stress, psychological functioning) and Quality of Life satisfaction of CHD patients involved in a CR program, 3) studying the influence of Type D personality risk factor on CR patients short-term outcome and Quality of Life satisfaction. Finally, taking into account that patients with Type D personality may deal with stress in a characteristic way [13], and to be afflicted by CHD may represent an highly meaningful stressor, the study also aims to 4) investigate coping reaction in CR patients and in Type D personality prior and after CR program.

Methods

\section{Study Design and Population}

Consecutive patients from the CR Unit of the Azienda Ospedaliero Universitaria Careggi, Florence, Italy, between March 2007 and June 2008, were recruited for the current study. Seventy patients satisfied inclusion criteria and agreed to participate. Inclusion criteria were: (1) age $\leq 75$ years (2) being able to understand and read Italian. Exclusion criteria were: (1) severe cognitive impairment, (2) substance abuse, (3) a history of severe psychiatric illness with psychotic features.

Within a mean time of two weeks from cardiac event patients were admitted to the rehabilitation programme as outpatients. Three or four weeks away from the cardiac event patients performed a symptom-limited stress test for functional capacity evaluation and to establish an appropriate physical training schedule. The symptom-limited stress test was also performed at the end of physical training program. Functional capacity was measured as Kgm.
Patients were invited to complete a set of psychological questionnaires at admission and 1 month after the completion of the CR program. Both sets of questionnaires were completed at the presence of a clinical psychologist.

The study protocol was approved by the Medical Ethics Committee of the Azienda Ospedaliero Universitaria Careggi in Florence. The study was conducted according to the Helsinki Declaration, and every patient provided a written informed consent.

\section{Socio-demographic and clinical variables}

Socio-demographic variables including gender, age, marital status, educational level and employment status were obtained using a set of questions in the questionnaire. Indication to CR (previous myocardial infarction, coronary artery bypass graft surgery, percutaneous coronary intervention), risk factors (hypertension, dyslipidaemia, depression, diabetes, overweight, smoking), cardiac function (left ventricular ejection fraction), functional capacity (effort tolerance), and prescribed medication, were obtained from patients' medical records.

\section{Cardiac Rehabilitation Program}

Cardiac Rehabilitation program was designed according to the national guidelines on CR. The program was carried out by a multidisciplinary clinical team and individually tailored to each patient. CR included clinical assessment and risk factor management, patient education, exercise training, dietary counselling, smoking cessation, psychosocial support. The clinical team comprised a cardiologist, a nurse, a physiotherapist, a clinical dietician, and a liaison psychiatrist. Patients were scheduled for an individual consultation with the physician within 1 week. A 4-week intensive CR program was planned. The treatment goals were identified individually based on the current national guidelines on pharmaceutical and non-pharmaceutical treatment.

Clinical assessment and risk factor management. High priority was given to clinical assessment and risk factor management during the intervention. The risk profile was systematically assessed, and the lifestyle changes achieved during the program were supported and reinforced. Pharmaceutical treatment was systematically optimized as part of the intervention to ensure optimal treatment and pharmaceutical compliance.

Patient education. The lifestyle intervention strategy was based on the stages of change model and self-efficacy theory. The lifestyle intervention was designed as group intervention, but individual counselling was included.

Exercise training. The supervised exercise training was a 4-week group program of 60 minutes five times weekly. The training plan was highly individualized and the patients were ECG-monitored; intensity, duration, and activity were individually tailored according to the initial test results and to the current guidelines for aerobic training.

Dietary counselling. Dietary counselling included initial individual assessment with the dietician, and individual prescription for special dietary conditions when required due to hypercholesterolemia, diabetes, obesity. 
Smoking cessation. Smoking cessation was introduced at the initial consultation with the physician and included individual counselling, nicotine replacement therapy, and biofeedback using systematic carbon monoxide measurements.

Psychosocial support. Psychosocial support was an integrated part of the program. Patients were screened for anxiety and depression and sent to the liaison psychiatrist and treated pharmaceutically when needed. Vocational guidance was offered as individual consultations with the social worker.

\section{Psychological Assessment}

\section{Type $D$ personality}

Type D personality was assessed with the Italian version [23] of Type D Scale-14 (DS-14) [5]. The questionnaire consists of 14 items divided into two subscales that measure negative affectivity (e.g. "I often feel unhappy") and social inhibition (e.g. "I am a closed person"). A standardized cutoff $\geq 10$ on both subscales indicates Type D caseness [5]. Items are answered on a five-point Likert scale (0-4) with a score range of 0 to 28 for each subscale. The psychometric properties of the DS14 are good with Cronbach's alpha $=0.88 / 0.86$ and test-retest reliability $r=0.72 / 0.82$ for the negative affectivity and social inhibition subscales, respectively [5].

\section{Psychological health status}

The Cognitive Behavioural Assessment Hospital Form (CBA-H), was used to assess depressive and anxious status, psychological functioning and behaviours at risk for heart disease. The CBA-H questionnaire is a wide-ranging tool for general psychological assessment and detection of critical areas of clinical interest, specifically developed with a cardiac population in mind, and validated for a population of Italian cardiac patients [24-26]. It consists of four sections: A, B, C, D, with a total of 152 dichotomous items (true/false). Each section covers a particular area of the individual's experience: Section A (emotional reactions to the ischaemic eventstate variables) includes anxiety, depression and health-care related fears. Section B (psychophysical stress in the past 3 months) includes a shift toward unexplained depressive mood, impairment in psychophysical well-being and perceived psychophysical stress. Section C (psychological characteristics supposed to persist across time and to be largely unaffected by medical or sociodemographic eventstrait variables) covers different areas: neuroticism, introversion/extroversion, social anxiety, hostility, inability to relax and Type A behaviour. Section D offers a qualitative analysis of risk habits and behaviours for heart disease such as smoke, work, stressful life events.

\section{Quality of Life}

The Italian version [27] of Quality of Life Enjoyment and Satisfaction Questionnaire (Q-LES-Q) [28] was administered to assess subjective quality of life. Q-LES-Q is a 90-items-self-report measure designed to quantify satisfaction and enjoyment in eight domains of functioning: physical health (13 items), feelings (14 items), work (12 items), household duties (10 items), school/work (10 items), leisure time activities (6 items), social relations (11 items), and general activities (14 items). There are also two single questions addressing overall satisfaction and medications satisfaction.

Each item is scored on a 5-point Likert scale that indicates the degree of enjoyment or satisfaction achieved during the past week $(1=$ very poor, $5=$ very good). Higher scores represent greater percentage of life enjoyment and satisfaction. Internal consistency (Cronbach [alpha] of 0.90) and test-retest reliability (coefficient of $0.74[\mathrm{~N}=54]$ ) of the QLES-Q have been established [28].

\section{Coping Style}

The Italian version [29,30] of Brief COPE Scale [31], an abbreviated version of the COPE [32], was administered to assess coping style. The questionnaire is a 28-item self report measure of coping skills, it consists of 14 domains/sub-scales (self-distraction, active coping, denial, substance use, use of emotional support, use of instrumental support, behavioural disengagement, venting of emotions, positive reframing, planning, humour, acceptance, religion, self-blame) of two items each. Participants are asked to respond to each item on a four-point Likert scale, indicating what they generally do and feel when they experience a stressful events $(1=\mathrm{I}$ have not been doing this at all; $4=\mathrm{I}$ have been doing this a lot). The Brief COPE has a similar factor structure to the original instrument, and good internal reliability [31].

\section{Data analyses}

Socio-demographic and clinical characteristics at baseline were compared between Type D and non Type D individuals using a Chi-square test. Negative Affectivity and Social Inhibition scores were separately entered into a mixed analysis of variance (ANOVA) with Type D and non Type D groups as between-subjects factor to test changing of type D personality subcomponents following CR.

Comparisons between psychological status, quality of life satisfaction and coping style, prior and after CR, were analysed using paired sample Student's t test, whereas unpaired t test was employed to explore differences between Type D and non Type D individuals at baseline.

A mixed ANOVA was used to explore the differences in coping style and in quality of life satisfaction between Type D and non Type D patients, prior and after CR.

In order to assess the potential clinical relevance of the psychological health status after CR, CBA-H scores were dichotomised according to the critical cut-off suggested by Authors [25]. Differences between Type D and non Type D groups in the percentage of patients whose CBA-H scores after CR exceeded the critical cut-off, were compared using Fisher's exact test.

For all tests, significance was set at $p<0.05$. The data were statistically analysed using SPSS 10.0 software. 


\section{Results}

\section{Patients characteristics and Type D personality}

Of the 70 enrolled patients, $59(84.3 \%)$ participated to the follow-up phase. Eleven patients did not accept to complete the follow-up phase and dropped-out, because they live too far from the hospital or because they had gone back to work and did not want to take further sick leave. No significant differences between completers and non-completers patients were found for socio-demographic variables (age, sex, marital status, education), risk factors and clinical characteristics.

Demographic and clinical characteristics of the sample $(n=59)$ at baseline are shown in Table 1. The percentage of Type $\mathrm{D}$ personality observed in this sample was 39\% (23/59). Table 1 shows baseline characteristics of the sample stratified by Type D. There were no significant differences between Type D and non Type D patients on baseline characteristics, including socio-demographics variables, diagnosis, prior cardiac events referred, functional capacity, pharmacological therapy, risks factors and use of psychopharmacological medication. However, Type D personality patients showed a significant $(p=0.034)$ greater percentage of hypertension risk factor $(73.9 \%)$ compared to non Type D personality patients (44.4\%). Psychopharmacological medication consisted of selective serotonin reuptake inhibitors (SSRIs) as antidepressants and benzodiazepines (BDZ) as anxyolitics-hypnotics.

After the CR Program the effort tolerance was significantly improved in the total sample (from $4181.2 \pm 2391.5$ to $5279.1 \pm 3096.1 \mathrm{Kgm}, p<0.001$ ) in the Type D Personality group (from $3958.3 \pm 2164.4$ to $4883.9 \pm 2786.8 \mathrm{Kgm}, p<0.001)$ and in the non Type D personality group (from $4159.7 \pm 2552.7$ to $5531.5 \pm 3291.7 \mathrm{Kgm}, p=0.003)$.

A change in Type D caseness was found after $\mathrm{CR}$ in $12.5 \%$ of patients (with $2.8 \%$ changing from non Type D to Type D and $9.7 \%$ from Type D to non Type D personality) while Type D caseness remained stable in $87.5 \%$ of patients, after CR.

The mixed ANOVA, performed to describe changing of Type D personality subcomponents following $C R$, revealed a significant main effect for time for Negative Affectivity $(\mathrm{F}=12.419, p=$ $0.001)$ and for Social Inhibition $(\mathrm{F}=9.735, p=$ 0.003 ) and a significant interaction for time by Type $\mathrm{D}$ for Social Inhibition $(\mathrm{F}=16.825$, $p<0.001)$. Post-hoc t-test showed a significant decrease over time in both Negative Affectivity and Social Inhibition scores in total sample (from $12.32 \pm 6.67$ to $10.12 \pm 5.79, p=0.001$; from $9.56 \pm 6.64$ to $8.30 \pm 5.33, p=0.049$, respectively) and in Type D personality group (from 17.5 \pm 4.2 to $14.5 \pm 4.1, p=0.005$; from $15.7 \pm 4.2$ to $11.8 \pm 5.0$, $p<0.001$, respectively).

\section{Psychological health status and Quality of Life}

Pre and Post CR comparison data are reported in Table 2. After CR programme all patients reported a significant improvement (t-test; $p<0.05)$ on CBA-H anxiety score, and in all CBA-H section B areas (psychophysical stress in the past 3 months), i.e. depressive mood, impairment in psychophysical well-being and perceived psychophysical stress. Except for inability to relax area, no significant differences in section $C$ (trait variables) were observed. Type A behaviour index decreased significantly after CR. In addition, there was a significant (t-test; $p<0.05)$ overall increase in Quality of Life satisfaction experienced by patients on almost all Q-LES-Q areas measured at follow-up phase, compared with baseline scores: physical health, feelings, household duties, leisure time activities, social relations, and general activities areas (Fig. 1). There was no significant difference in psychological health status pre- and post-CR between patients using or not using psychopharmacological medication.

At baseline, the 23 Type D Personality patients, referred a general lower level of psychological health status, in terms of significant (t-test; $p<0.05)$ higher anxiety $(p=0.001)$, higher depressive mood $(p<0.001)$, lower level of psychophysical well-being $(p=0.001)$, and higher level of perceived psychophysical stress $(p=0.032)$ when compared with non-Type D Personality patients (see Table 3 ). Type D Personality group showed also significant $(p<0.05)$ differences on stable trait variables, i.e. significant higher level of neuroticism, social anxiety, haste and impatience and interpersonal difficulties, together with significant lower level of extroversion and inability to relax, compared with nonType D Personality group. In addition, Type D Personality patients were less likely to report Quality of Life enjoyment at Q-LES-Q, when compared with non Type D Personality patients. Type D patients scored significantly lower on Quality of Life satisfaction in physical health, feelings and emotions, social relations and in the global satisfaction subscale of general activities $(p<0.05)$.

To examine the differences in Quality of Life perception between Type D and non Type D patients, prior and after CR, a mixed ANOVA was employed. There was a significant main effect for time for all Q-LES-Q domains (physical health $[\mathrm{F}=$ $10.911, p=0.002]$, feelings $[\mathrm{F}=4.518, p=0.038]$, household duties $[\mathrm{F}=6.211, p=0.018]$, leisure time activities $[\mathrm{F}=6.932, p=0.011]$, social relations $[\mathrm{F}$ $=4.721, p=0.034]$, and general activities $[\mathrm{F}=$ $18.435, p<0.001]$ but not for the work satisfaction subscale) showing an overall improvement in Quality of Life satisfaction of patients. The between subject factor (Type D caseness) was significant for physical health $[\mathrm{F}=12.921 p<0.001]$, feelings $[\mathrm{F}=$ $21.054, p<0.001]$, social relations $[\mathrm{F}=18.649$, $p<0.001]$, and general activities $[\mathrm{F}=16.565$, $p<0.001]$. The time by Type D interaction was not significant, indicating that Type D caseness influenced significantly Quality of Life enjoyment and satisfaction, independently from CR treatment.

Clinical relevance of Type D Personality on psychological health status using critical cut-off

In order to assess the potential clinical relevance of patients' psychological health status after CR, CBA-H scores were dichotomised according to the critical cut-off suggested by the Authors [25]. Comparisons revealed that, after $\mathrm{CR}$, a significantly [Fisher's exact test, $p<0.05$ ] higher percentage of pa- 
Table 1. - Sample characteristics stratified by Type D personality (baseline)

\begin{tabular}{|c|c|c|c|c|c|}
\hline & & $\begin{array}{c}\text { Total sample } \\
(\mathrm{n}=59)\end{array}$ & $\begin{array}{l}\text { Type D } \\
(\mathrm{n}=23)\end{array}$ & $\begin{array}{c}\text { Non-Type D } \\
(\mathrm{n}=36)\end{array}$ & $p$ \\
\hline \multicolumn{6}{|l|}{ Socio-demographics } \\
\hline Male & & $46(78.0)$ & $17(73.9)$ & 29 (80.6) & ns \\
\hline Age, mean (SD) & & $58.3(8.7)$ & $56.7(9.0)$ & $59.3(8.5)$ & ns \\
\hline Living alone & & $11(18.6)$ & $5(21.7)$ & $6(16.7)$ & ns \\
\hline \multirow[t]{5}{*}{ Marital status } & unmarried & $13(22.0)$ & $6(26.1)$ & $7(19.4)$ & ns \\
\hline & married & $37(62.7)$ & $13(56.6)$ & $24(66.7)$ & $\mathrm{ns}$ \\
\hline & widower/widow & $4(6.8)$ & $1(4.3)$ & $3(8.3)$ & ns \\
\hline & separated & $3(5.1)$ & $2(8.7)$ & $1(2.8)$ & ns \\
\hline & divorced & $2(3.4)$ & $1(4.3)$ & $1(2.8)$ & ns \\
\hline \multirow[t]{4}{*}{ Education } & primary & $13(22.0)$ & $5(21.7)$ & $8(22.2)$ & ns \\
\hline & secondary & $23(39.0)$ & $8(34.8)$ & $15(41.7)$ & ns \\
\hline & high & $21(35.6)$ & $9(39.2)$ & $12(33.3)$ & ns \\
\hline & degree & $2(3.4)$ & $1(4.3)$ & $1(2.8)$ & $\mathrm{ns}$ \\
\hline \multirow[t]{4}{*}{ Employment status } & retired & $23(38.9)$ & $7(30.4)$ & $16(44.4)$ & ns \\
\hline & housewife & $2(3.4)$ & $1(4.3)$ & $1(2.8)$ & ns \\
\hline & not employed & $4(6.8)$ & $3(13.0)$ & $1(2.8)$ & ns \\
\hline & employed & $30(50.9)$ & $11(47.8) 19$ & $(52.8)$ & ns \\
\hline \multicolumn{6}{|l|}{ Risks factors } \\
\hline Hypertension & & $33(55.9)$ & $17(73.9)$ & $16(44.4)$ & 0.034 \\
\hline Smoke & & $35(59.3)$ & $14(60.9)$ & $21(58.3)$ & ns \\
\hline Dyslipidemia & & $35(59.3)$ & $18(78.2)$ & $16(47.3)$ & ns \\
\hline Depression & & $9(15.3) 4$ & $(17.4)$ & $5(13.9)$ & $\mathrm{ns}$ \\
\hline Obesity & & $15(25.4)$ & $4(17.4)$ & $11(30.6)$ & ns \\
\hline Diabetes mellitus & & 7 (11.9) & $3(13.0)$ & $4(11.1)$ & ns \\
\hline No physical activity & & $2(3.4)$ & $1(4.3)$ & $1(2.8)$ & ns \\
\hline None & & $3(5.1)$ & $0(0.0)$ & $3(8.3)$ & ns \\
\hline \multicolumn{6}{|l|}{ Clinical data } \\
\hline \multicolumn{6}{|l|}{ Diagnosisa } \\
\hline MI & & $39(66.1)$ & $17(73.9)$ & $22(61.1)$ & ns \\
\hline PCI & & $35(59.3)$ & $16(69.6)$ & $19(52.8)$ & ns \\
\hline $\mathrm{CABG}$ & & 7 (11.9) & $1(4.3)$ & $6(16.7)$ & ns \\
\hline Valvoular Surgery & & $4(5.6)$ & $0(0.0)$ & 4 (8.7) & ns \\
\hline Heart Failure & & $4(5.6)$ & $0(0.0)$ & $4(8.7)$ & $\mathrm{ns}$ \\
\hline PM/ICD & & $7(9.7)$ & $2(7.7)$ & $5(10.9)$ & ns \\
\hline \multicolumn{6}{|c|}{ Number of cardiac event ${ }^{b}$ prior to referral event } \\
\hline 0 & & $47(79.7)$ & 19 (82.6) & $28(77.8)$ & ns \\
\hline 1 & & $5(8.5)$ & $1(4.3)$ & $4(11.1)$ & ns \\
\hline 2 & & $6(10.2)$ & $2(8.7)$ & $4(11.1)$ & ns \\
\hline 3 & & $1(1.7)$ & $1(4.3)$ & $0(0.0)$ & ns \\
\hline \multicolumn{6}{|c|}{ Cardiac Function } \\
\hline Ejection Fraction $\mathrm{Me}$ & in (SD) & $50.05(11.62)$ & $50.09(13.29)$ & $50.03(10.61)$ & ns \\
\hline \multicolumn{6}{|c|}{ Functional capacity } \\
\hline Effort tolerancec $\mathrm{Me}$ & (SD) & $4181.2(2391.5)$ & $3958.3(2164.4)$ & $4159.7(2552.7)$ & ns \\
\hline \multicolumn{6}{|l|}{ Pharmacological therapy } \\
\hline Anti-platelets & & $56(94.9)$ & $23(100)$ & $33(91.7)$ & ns \\
\hline Antiarrhythmic & & $2(3.4)$ & $0(0)$ & $2(5.6)$ & ns \\
\hline ACE inhibitors & & $56(94.9)$ & $22(95.6)$ & $34(94.5)$ & ns \\
\hline Diuretics & & $11(18.6)$ & $3(13.0)$ & $8(22.2)$ & ns \\
\hline Antialdosterone diur & & $17(28.8)$ & $6(26.1)$ & $11(30.6)$ & ns \\
\hline Betablockers & & $48(81.3)$ & $19(82.6)$ & $29(80.5)$ & ns \\
\hline Digitalis & & $0(0)$ & $0(0)$ & $0(0)$ & ns \\
\hline Hypoglicemic & & $7(11.9)$ & $3(13.0)$ & $4(11.1)$ & ns \\
\hline Statins & & $52(88.1)$ & $21(91.3)$ & $31(86.1)$ & ns \\
\hline Nitrates & & $6(10.2)$ & $2(7.7)$ & $4(11.1)$ & ns \\
\hline Calcium antagonists & & $4(6.8)$ & $1(4.3)$ & $3(8.4)$ & ns \\
\hline Anticoagulants & & $3(5.1)$ & $0(0)$ & $3(8.4)$ & $\mathrm{ns}$ \\
\hline \multicolumn{6}{|c|}{ Use of psychopharmacological medication } \\
\hline Antidepressants & & $9(15.2)$ & $6(26.1) 3$ & $(8.3)$ & ns \\
\hline Anxiolytics & & $12(20.3)$ & $8(34.8)$ & $6(16.6)$ & ns \\
\hline
\end{tabular}

Data are presented as $\mathrm{n}(\%)$ unless otherwise indicated.

aMI myocardial infarction, PCI percutaneous coronary intervention, CABG coronary artery bypass grafting.

b Previous myocardial infarction, percutaneous coronary intervention or coronary artery bypass grafting.

$\mathrm{P}<0.05$, Chi-square test

cmeasured as $\mathrm{Kgm}$ 


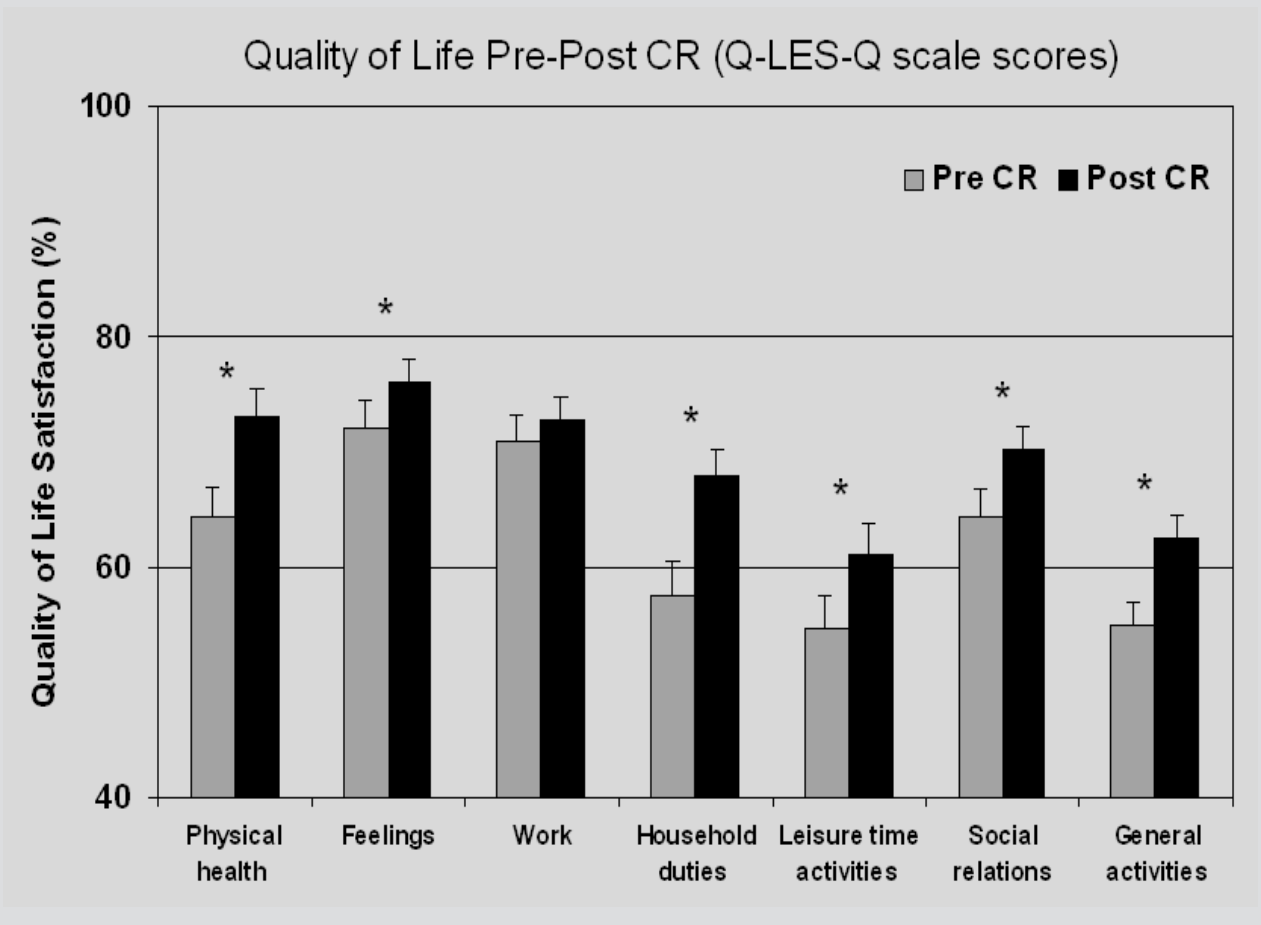

Figure 1. - Patients' Quality of Life satisfaction pre and post CR. Two-tailed paired-sample t-test $p<0.05$. tients in the Type D group continued to show scores exceeding the critical cut-off, indicative of clinical relevance, for anxiety ( $p$ $=0.003$ ), depressive $\operatorname{mood}(p=0.001)$, impairment in psychophysical well-being $(p=0.002)$, perceived psychophysical stress $(p=0.002)$, neuroticism $(p=0.012)$, interpersonal difficulties $(p<0.001)$, introversion $(p=0.047)$ and social anxiety $(p=0.045)$, compared to non Type D group (Table 4).

\section{Coping style}

Prior and after CR the most used problemfocused coping strategies included Planning

Table 2. - Mean (SD) CBA-H score Pre and Post CR $(n=59)$

\begin{tabular}{|c|c|c|c|c|c|}
\hline$C B A-H$ & \multicolumn{2}{|c|}{ Pre CR } & \multicolumn{2}{|c|}{ Post CR } & $p$ \\
\hline A1.Anxiety & 3.14 & $(2.66)$ & 2.44 & $(2.44)$ & 0.049 \\
\hline A2.Health-care related fears & 1.92 & $(1.21)$ & 1.69 & $(1.12)$ & $\mathrm{ns}$ \\
\hline A3.Depression & 0.51 & $(0.73)$ & 0.31 & $(0.70)$ & ns \\
\hline B1.Emotional instability-depressive mood & 4.36 & $(2.88)$ & 2.47 & $(2.50)$ & $<0.001$ \\
\hline B2.Psychophysical well-being & 2.86 & $(1.86)$ & 4.44 & $(1.65)$ & $<0.001$ \\
\hline B3.Perceived psychophysical stress & 3.36 & $(1.85)$ & 1.92 & $(1.79)$ & $<0.001$ \\
\hline C1.Neuroticism & 4.07 & $(2.83)$ & 3.63 & $(2.99)$ & $\mathrm{ns}$ \\
\hline C2.Extroversion/Introversion & 5.41 & $(1.76)$ & 5.51 & $(1.74)$ & $\mathrm{ns}$ \\
\hline C3.Social anxiety & 2.76 & $(1.64)$ & 2.56 & $(1.91)$ & ns \\
\hline C4.Haste and impatience & 4.42 & $(1.84)$ & 4.15 & $(1.95)$ & $\mathrm{ns}$ \\
\hline C5.Excessive involvement & 4.92 & $(1.64)$ & 4.66 & $(1.71)$ & $\mathrm{ns}$ \\
\hline C6.Hostility & 0.93 & $(0.96)$ & 0.75 & $(0.92)$ & $\mathrm{ns}$ \\
\hline C7.Inability to relax & 2.49 & $(0.77)$ & 2.78 & $(0.49)$ & 0.002 \\
\hline C8.Interpersonal difficulties & 1.90 & $(1.26)$ & 1.80 & $(1.35)$ & $\mathrm{ns}$ \\
\hline C9.Leadership/competitiveness & 2.39 & $(0.97)$ & 2.12 & (1.08) & $\mathrm{ns}$ \\
\hline C10.Irritability & 1.34 & $(0.92)$ & 1.56 & $(0.95)$ & ns \\
\hline Type A behaviour & 8.83 & $(3.77)$ & 7.34 & $(3.92)$ & $<0.001$ \\
\hline
\end{tabular}

Data are presented as Mean (SD) unless otherwise indicated.

CBA-H: Lower scores represents better health status except for B2-Psychophysical well-being for which higher scores represents better health status.

$\mathrm{P}<0.05$, two-tailed paired-sample test 
Table 3. - CBA-H, Q-LES-Q scale scores. Type D-non Type D Personality comparison at baseline

\begin{tabular}{|c|c|c|c|}
\hline & $\begin{array}{l}\text { non Type } \\
(\mathrm{n}=36)\end{array}$ & $\begin{array}{l}\text { D Type D } \\
(\mathrm{n}=23)\end{array}$ & $p$ \\
\hline \multicolumn{4}{|l|}{$C B A-H$} \\
\hline A1.Anxiety & $2.4 \pm 2.6$ & $4.6 \pm 2.3$ & 0.001 \\
\hline A2.Health-care related fears & $1.8 \pm 1.0$ & $2.0 \pm 1.4$ & ns \\
\hline A3.Depression & $0.5 \pm 0.7$ & $0.7 \pm 0.8$ & ns \\
\hline B1.Emotional instability-depressive mood & $3.3 \pm 2.6$ & $5.7 \pm 2.8$ & $<0.001$ \\
\hline B2.Psychophysical well-being & $3.6 \pm 1.7$ & $2.0 \pm 1.8$ & 0.001 \\
\hline B3.Perceived psychophysical stress & $2.8 \pm 2.0$ & $4.0 \pm 1.5$ & 0.032 \\
\hline C1.Neuroticism & $3.2 \pm 2.5$ & $5.4 \pm 2.9$ & 0.005 \\
\hline C2.Extroversion/Introversion & $6.1 \pm 1.1$ & $4.5 \pm 2.0$ & 0.001 \\
\hline C3.Social anxiety & $2.1 \pm 1.5$ & $3.4 \pm 1.8$ & 0.004 \\
\hline C4.Haste and impatience & $4.0 \pm 2.0$ & $4.9 \pm 1.3$ & ns \\
\hline C5.Excessive involvement & $5.2 \pm 1.6$ & $4.5 \pm 1.5$ & 0.021 \\
\hline C6.Hostility & $0.8 \pm 0.9$ & $1.1 \pm 1.1$ & ns \\
\hline C7.Inability to relax & $2.6 \pm 0.7$ & $2.1 \pm 1.0$ & 0.023 \\
\hline C8.Interpersonal difficulties & $1.5 \pm 1.1$ & $2.6 \pm 1.2$ & $<0.001$ \\
\hline C9.Leadership/competitiveness & $2.4 \pm 1.0$ & $2.5 \pm 0.9$ & ns \\
\hline C10.Irritability & $1.4 \pm 0.9$ & $1.3 \pm 0.9$ & ns \\
\hline \multicolumn{4}{|l|}{$Q-L E S-Q$} \\
\hline Physical health & $65.2 \pm 19.0$ & $57.6 \pm 19.8$ & 0.015 \\
\hline Feelings & $76.8 \pm 15.7$ & $62.3 \pm 18.7$ & $<0.001$ \\
\hline Work & $72.9 \pm 13.8$ & $67.8 \pm 24.0$ & $\mathrm{~ns}$ \\
\hline Household duties & $59.6 \pm 22.2$ & $56.9 \pm 23.9$ & ns \\
\hline Leisure time activities & $57.7 \pm 21.8$ & $50.5 \pm 16.2$ & $\mathrm{~ns}$ \\
\hline Social relations & $70.4 \pm 16.4$ & $56.7 \pm 17.0$ & 0.003 \\
\hline General activities & $57.9 \pm 15.5$ & $47.1 \pm 10.8$ & 0.001 \\
\hline
\end{tabular}

(prior and after CR: $6.66 \pm 1.75 ; 6.63 \pm 1.46$, respectively) and Active Coping (6.27 $\pm 1.76 ; 6.16 \pm 1.60)$, while the most used emotional focused coping strategies were Acceptance $(6.22 \pm 1.82 ; 6.45 \pm 1.53)$ and Positive Reframing (5.64 $\pm 1.85 ; 5.72 \pm 1.80)$. The most used coping responses less useful were Self Blame $(5.35 \pm 1.66 ; 5.08 \pm 1.65)$ and Self Distraction (5.13 $\pm 2.05 ; 4.94 \pm 1.92)$.

Pre and post $\mathrm{CR}$ program comparison showed a significant ( $\mathrm{t}$-test; $p<0.05)$ increase in patients' use of Denial and a significant lesser (t-test; $p<0.05)$ Substance Use coping style in response to stressful events, whereas no significant difference was ob- served for the other Brief-COPE coping domains. Comparison between Type D Personality and non Type D Personality patients, prior CR, found a significant higher use of Self-Blame by Type D Personality patients $(p=0.046)$.

Mixed ANOVA analysis revealed a significant between subject factor (Type D) for Venting of emotions coping style $[\mathrm{F}=5.048, p=0.029]$ and a significant main effect for time for Denial $[\mathrm{F}=$ 4.763, $p=0.033]$ and for Substance Use $[\mathrm{F}=3.764$, $p=0.05]$. Time by Type D interaction was found significant for Self-Blame coping style $[\mathrm{F}=5.342$, $p=0.024]$. 
Table 4. - CBA-H clinical scores. Type D-non Type D Personality comparison post CR

\begin{tabular}{|c|c|c|c|}
\hline & $\begin{array}{l}\text { Non Type D } \\
(\mathrm{n}=36) \\
\text { Freq } \%\end{array}$ & $\begin{array}{l}\text { Type D } \\
(\mathrm{n}=23) \\
\text { Freq } \%\end{array}$ & $p$ \\
\hline \multicolumn{4}{|l|}{$C B A-H$} \\
\hline A1.Anxiety & 13.9 & 39.1 & 0.003 \\
\hline A2.Health-care related fears & 16.7 & 39.1 & ns \\
\hline A3.Depression & 8.3 & 13.0 & ns \\
\hline B1.Emotional instability-depressive mood & 8.3 & 47.8 & 0.001 \\
\hline B2.Psychophysical well-being & 11.1 & 47.8 & 0.002 \\
\hline B3.Perceived psychophysical stress & 5.5 & 39.1 & 0.002 \\
\hline C1.Neuroticism & 22.2 & 56.5 & 0.012 \\
\hline C2.Extroversion/Introversion & 5.6 & 26.1 & 0.047 \\
\hline C3.Social anxiety & 11.1 & 34.8 & 0.045 \\
\hline C4.Haste and impatience & 38.9 & 56.5 & ns \\
\hline C5.Excessive involvement & 61.1 & 39.1 & ns \\
\hline C6.Hostility & 8.3 & 21.7 & ns \\
\hline C7.Inability to relax & 2.8 & 4.4 & ns \\
\hline C8.Interpersonal difficulties & 33.3 & 87.0 & $<0.001$ \\
\hline C9.Leadership/competitiveness & 30.6 & 47.8 & ns \\
\hline C10.Irritability & 47.2 & 47.8 & ns \\
\hline \multicolumn{4}{|c|}{$\begin{array}{l}\text { Data are presented as frequencies }(\%) \text { of patients whose CBA-H scores after CR exceeded the critical cut-off indicative of clinic } \\
\text { relevance. } \\
P<0.05 \text {, Fisher's exact test }\end{array}$} \\
\hline
\end{tabular}

\section{Discussion}

In the present study, we investigated Quality of Life satisfaction and psychological health status of CHD patients involved in a CR program. As expected, consistently with previous studies $[5,19,20,22]$, results showed an overall improvement of CR patients in psychological health, a significant reduction of anxiety, depressive mood, psychophysical stress and impairment, and an overall increase of Quality of Life enjoyment, after CR, confirming that programs comprising all core components of cardiac rehabilitation may be effective to enhance patients well-being.

The first aim of the study was to verify the presence of Type D personality in the current CR sample. Results show a higher percentage of Type D personality (39\%) in this sample if compared with prevalence reported in Italian [23] and in European $[5,33,34]$ CHD population, and in one study conducted in an European CR setting [22]. The significant larger percentage of patients with hypertension risk factor in the current sample may have contribute to the high rate of Type D personality. In fact, a previous study [5] observed Type D to be more prevalent among patients with hypertension (53\%). In ad- dition, Type $\mathrm{D}$ was associated with increased blood pressure reactivity to stress in young, healthy adults [35]. In line to others findings [22], we observed that the majority of the Type D caseness $(87.5 \%)$ remained stable, after CR.

Type D personality resulted to be a risk factor for Quality of Life and psychological health status. Prior to CR Type D patients were found to report a significant lower Quality of Life satisfaction in several areas such as physical health, feelings and emotions, social relations, and in overall satisfaction for daily activities, compared to patients with non Type $\mathrm{D}$ personality. In addiction, after $\mathrm{CR}$, the influence of Type D personality on Quality of Life satisfaction remained significant, affecting most of the mentioned areas (physical health, feelings and emotions, social relations and in global satisfaction for daily activities). Furthermore, we observed Type D to be associated with a significant greater level of psychological impairment, greater anxiety, depressive mood, psychophysical impairment and stress, prior to CR. Type D patients revealed higher level of neuroticism, social anxiety, introversion, haste and impatience, interpersonal difficulties, inability to relax. Finally, despite the overall significant improvement observed after CR, Type D personality 
was still significantly associated with a clinically relevant poor psychological status. Hence results of our study pointed out that Type D played a significant clinically relevant role, on psychological health outcome in CR.

A significant reduction in both Type D subcomponents - Negative Affectivity and Social Inhibition - observed in Type D patients following CR was a further result of our study. This finding is not in agreement with other studies [5,21] which found no significant reduction in Type D scores after standard $\mathrm{CR}$, but it is partially in line with results of two previous studies, [21,22] which found a change in Social Inhibition in Type D who participated in a CR extended program, and in participants of a program including all core components of CR, respectively. Characteristics of the context and setting in which a CR occurs might offer a possible explanation to the reduction of Negative Affectivity and Social Inhibition observed in the present Type D group. It should be noted [36] that positive effects of CR were also related to the effect of mediating social mechanisms triggered by attending to $\mathrm{CR}$ in formal and informal groups. Hence, to being part of a group ('being in the same boat'), perceiving similarities between other people attending rehabilitation, sharing emotion, and being in close proximity to other cardiac patients at different stages in rehabilitation may unsurprisingly enhance personal and social confidence, and provide emotional support to patients and an increased sense of control over the disease process [19]. The first implication for Type D intervention in CR setting would be the active promotion of informal social occasions during CR, together with adjunctive emotion and stress management interventions. However, further studies are needed to explore this hypothesis.

Finally, with regard to the findings on coping style, the present study showed that the most used problem-focused coping strategies by CR participants were Planning and Active coping, the most used emotion-focused coping strategies were Acceptance and Positive Reframing, whereas the most used maladaptive strategies were Self-Blame and Self-Distraction. Comparison pre and post CR showed an increased use of Denial and a lesser use of Substance Use coping style. Some coping reactions are known to be generally adaptive, while previous research has shown that others seem to be potentially dysfunctional [31]. Emotion-oriented coping strategies in the long term may be less adaptive than problem-oriented strategies, however, the impact of these coping strategies appears to depend on the specific stressful situation $[37,38]$. Type D personality was found to be associated with a greater use of coping strategy of Venting of emotions (i.e. entails a focusing on stress) which is considered a maladaptive strategy as by focusing on and venting emotion, people dwell on their distress and distract themselves from active coping [32]. Furthermore, prior to CR Type D, compared to non Type D patients, used significantly more a Self-Blame coping style (i.e. criticizing oneself for responsibility in the situation) which has been found to be a predictor of poor adjustment under stress $[39,40]$. Nevertheless, following $\mathrm{CR}$ the use of Self-Blame coping style significantly decreased, indicating a possible improvement in coping abilities by Type D patients. However, these preliminary findings need further investigations, as important questions about coping style in CR setting remained.

Limitations of the present study include the lack of a wait list control group and a relatively small number of patients, although our results reached significance. In addition, the brief duration of the intesive CR program and differences in the duration between Italian and Europe or USA CR program should be considered for the generalizability of the present findings.

Strengths of the study comprise the use of a wide range of psychological assessment and the employment of a battery specifically developed for the Italian CHD population (CBA-H). Moreover, the study extends the current research on Type D patients outcome, following CR, with additional variables such as Quality of Life enjoyment and coping strategy, and provides further information on Italian CR patients population.

In summary our study provides findings on Quality of Life and short-term psychological outcome in Type D and non Type D patients, following CR. After CR, psychological status and Quality of Life satisfaction of CHD patients were found to be enhanced. Nevertheless, Type D personality patients reported a significant higher level of psychological impairment in terms of anxiety, depressive mood, psychophysical well-being, perceived psychophysical stress, social anxiety, interpersonal difficulties and a significant lower Quality of Life satisfaction. Moreover, the impairment in psychological health outcome remained clinically relevant for a significant higher percentage of Type D compared to non Type D patients, after CR. In addiction, although the subcomponents (Negative Affectivity and Social Inhibition) of Type D personality decreased following CR, the majority of Type D remained stable in their caseness. Type D personality seemed associated with maladaptive coping strategies, as well. Therefore, importance of assessment for Type D personality is warranted in CR setting so as additional interventions seem required to enhance the outcome of these patients defined in letterature at high-risk. Further studies are needed to explore the hypothesis of intervention for Type D patients in CR setting with the active promotion of informal social occasion during $\mathrm{CR}$, together with adjunctive emotion and stress management intervention.

\section{Riassunto}

Background: La personalità di Tipo D rappresenta un fattore di rischio in termini di ridotta qualità della vita ed outcome negativo nei pazienti con malattia coronarica. Pochi studi hanno indagato la personalità di Tipo D nell' ambito della riabilitazione cardiologica. Nessuno studio ha valutato la personalità di Tipo $D$ nei pazienti che seguono un programma di riabilitazione cardiologica intensiva. Questo studio si propone di a) verificare la presenza di personalità di Tipo D tra i pazienti ammessi alla riabilitazione cardiologica; b) indagare lo stato di 
salute psicologica, la qualità della vita e le strategie di coping di questi pazienti; c) testare l'influenza della personalità di Tipo D sull'outcome dopo la dimissione dalla riabilitazione.

Metodi: Al momento dell'ammissione e ad 1 mese dalla dimissione sono stati raccolti $i$ dati su 59 pazienti afferiti ad un programma intensivo di riabilitazione cardiologica in Day Hospital della durata di 4 settimane, mediante una serie di questionari self-report. Le variabili sono state misurate utilizzando le scale CBA-H, DS-14, Q-LES-Q e Brief COPE.

Risultati: Nel campione di studio è stata osservata una percentuale del $39 \%$ di pazienti con personalità di Tipo D. Al momento dell' ammissione, $i$ pazienti con personalità di Tipo $D$ mostravano un livello di salute psicologica e di soddisfazione per la qualità della vita significativamente inferiore, rispetto ai pazienti con personalità non di Tipo $D(p$ $<0.05$ ). Dopo la riabilitazione, una percentuale significativa di pazienti con personalità di Tipo D, ha continuato a mostrare una compromissione psicologica in termini di ansia $(p=0.003)$, umore depresso $(p=0.001)$, ridotto benessere psicofisico $(p=0.002)$, stress psicofisico percepito $(p=0.002)$, difficoltà interpersonali $(p<0.001)$ ed ansia sociale $(p=0.045)$. Nel campione di studio, inoltre, la personalità di Tipo D è associata all' uso significativamente maggiore di strategie di coping disadattive $(p<0,05)$.

Conclusioni: La personalità di Tipo D sembra giocare, in maniera significativa, un ruolo clinicamente rilevante sull'outcome relativo alla salute psicologica dei pazienti in riabilitazione cardiaca. I pazienti con personalità di Tipo D, rispetto ai soggetti con personalità non di Tipo D, mostrano un livello significativamente più elevato di compromissione psicologica, in termini di sintomi d'ansia, umore depresso, stress psicofisico percepito, ridotto benessere psicofisico, difficoltà interpersonali, ansia sociale ed un livello significativamente inferiore di soddisfazione per la qualità di vita, prima e dopo la riabilitazione. La personalità di Tipo D sembra anche associarsi a strategie di coping maggiormente disadattive. Lo studio evidenzia l'importanza della valutazione per la personalità di Tipo D nel contesto riabilitativo e suggerisce, inoltre, la necessità di interventi aggiuntivi, per sostenere l'outcome di questi pazienti definiti in letteratura ad alto rischio.

\section{ABBREVIATIONS}

CBA-H = Cognitive Behavioural Assessment Hospital Form CHD $=$ Coronary Heart Disease

$\mathbf{C R}=$ Cardiac Rehabilitation

DS14 = Type D Scale

Q-LES-Q = Quality of Life Enjoyment and Satisfaction Questionnarie

QoL = Quality of Life

Acknowledgments: We are grateful to the study participants for their time and interest in the project.

This work was supported by a grant from 'Ente Cassa di Risparmio di Firenze’, Florence, Italy.

\section{References}

1. Hemingway H, Marmot M. Psychosocial factors in the aetiology and prognosis of coronary heart disease: systematic review of prospective cohort studies. BMJ 1999; 318: 1460-1467.

2. Rozanski A, Blumenthal JA, Davidson KW, Saab PG, Kubzansky L. The epidemiology, pathophysiology, and management of psychosocial risk factors in cardiac practice: the emerging field of behavioral cardiology. $J \mathrm{Am}$ Coll Cardiol 2005; 45: 637-651.

3. Giallauria F, Battimiello V, Veneziano M, et al. L'importanza e il ruolo dei fattori di rischio psicosociale in cardiologia. Monaldi Arch Chest Dis 2007; 68: 74-80.

4. Denollet J, Sys SU, Brutsaert DL. Type D Personality and Mortality After Myocardial Infarction. Psychosom Med 1995; 57: 582-591.

5. Denollet J. DS14: Standard Assessment of Negative Affectivity, Social Inhibition and Type D Personality. Psychosom Med 2005; 67: 89-97.

6. Denollet J, De Potter B. Coping subtypes for men with coronary heart disease: relationship to well-being, stress, and Type A behaviour. Psychol Med 1992; 22: 667-684.

7. Denollet J. Bio-behavioural research on coronary heart disease: where is the person? J Behav Med 1993; 16 115-141.

8. Denollet J, Sys SU, Stroobant N, Rombouts H, Gillebert TC, Brutsaert DL. Personality as independent predictor of long-term mortality in patients with coronary heart disease. Lancet 1996; 347: 417-421.

9. Denollet J. Personality and coronary heart disease: the type-D Scale-16 (DS16). Ann Behav Med 1998; 20: 209-215.

10. Pedersen SS, Middel B. Increased vital exhaustion among Type-D patients with ischaemic heart disease. $J$ Psychosom Res 2001; 51: 443-449.

11. Pedersen SS, Denollet J. Type D Personality, Cardiac Events, and Impaired Quality of Life: a review. Eur J Cardiovasc Prev Rehabil 2003; 10: 241-248.

12. Denollet J, Perdersen SS, Ong AT, Erdman RA, Serruys PW, van Domburg RT. Social inhibition modulates the effect of negative emotions on cardiac prognosis following percutaneous coronary intervention in the drug eluting stent era. Eur Heart J 2006; 27: 171-7.

13. Denollet J. Type D personality: a Potential Risk Factor Refined. J Psychosom Res 2000; 49: 255-266.

14. Kupper N, Denollet J. Type D Personality a Prognostic Factor in Heart Disease: Assessment and Mediating Mechanism. J Personal Assessment 2007; 89: 265-276.

15. Lavie CJ, Milani RV. Adverse psychological and coronary risk profiles in young patients with coronary artery disease and benefits of formal cardiac rehabilitation. Arch Intern Med 2006; 166: 1878-1883.

16. Cohen RA, Moser DJ, Clark MM, et al. Neurocognitive functioning and improvement in quality of life following participation in cardiac rehabilitation. Am J Cardiol 1999; 83: 1374-1378.

17. Williams MA, Ades PA, Hamm LF, et al. Clinical evidence for a health benefit from cardiac rehabilitation: An update. Am Heart $J$ 2006; 152: 835-841.

18. Balady GJ, Williams MA, Ades PA, et al. Core components of cardiac rehabilitation/secondary prevention programs: 2007 update: a scientific statement from the American Heart Association Exercise, Cardiac Rehabilitation, and Prevention Committee, the Council on Clinical Cardiology; the Councils on Cardiovascular Nursing, Epidemiology and Prevention, and Nutrition, Physical Activity, and Metabolism; and the American Association of Cardiovascular and Pulmonary Rehabilitation. Circulation 2007; 115: 2675-2682.

19. Denollet J, Brutsaert DL. Enhancing emotional well-being by comprehensive rehabilitation in patients with coronary heart disease. Eur Heart J 1995; 16: 1070-1078. 
20. Denollet J, Brutsaert DL. Reducing Emotional Distress Improves Prognosis in Coronary Heart Disease.9-Year Mortality in a Clinical Trial of Rehabilitation. Circulation 2001; 104: 2018.

21. Karlsson MR, Edström-Plüss C, Held C, Henriksson P, Billing E, Wallén NH. Effects of expanded cardiac rehabilitation on psychosocial status in coronary artery disease with focus on type D characteristics. J Behav Med 2007; 30: 253-261.

22. Pelle AJ, Erdman RA, van Domburg RT, Spiering M, Kazemier M, Pedersen SS. Type D patients report poorer health status prior to and after cardiac rehabilitation compared to non-type D patients. Ann Behav Med 2008; 36: 167-175.

23. Gremigni P, Sommaruga M. Type D personality, a relevant construct in cardiology. Preliminary validation study of the Italian questionnaire. Psicot Cogn Comport 2005; 11: 7-18.

24. Zotti AM, Bettinardi O, Bertolotti G, Michielin P, Sanavio E, Vidotto G. Forma H della batteria CBA 2.0. Edizione speciale GISSI-2. Bollettino Psicologia Applicata 1989; 191-2: 57-62.

25. Zotti AM, Bertolotti G, Michielin P, Sanavio E, Vidotto G. Linee guida per lo screening di tratti di personalità, cognizioni e comportamenti avversi alla salute. Manuale d'uso per il CBA Forma Hospital. Advances in Rehabilitation. Aggiornamenti in Medicina Riabilitativa; 8. Pavia: Edizione Maugeri Foundation Books, 2000.

26. Bettinardi O, Zotti AM. II CBA Forma H: una misurazione dei comportamenti avversi alla salute. In: Sanavio E, Vidotto G. CBA: 10 anni di ricerche. Torino: UPSEL Editore, 1995.

27. Rossi A, Rucci P, Mauri M, et al. Validity and reliability of the Italian version of the Quality of Life, Enjoyment and Satisfaction Questionnaire. Qual Life Res 2005; 14: 2323-2328.

28. Endicott J, Nee J, Harrison W, Blumenthal R. Quality of life enjoyment and satisfaction questionnaire: A new measure. Psychopharmacol Bull 1993; 29: 321-326.
29. Sica C, Novara C, Dorz S, Sanavio E. Coping Orientation to Problems Experienced (COPE): traduzione e adattamento italiano Bollettino di Psicologia, 1997; 223: 25-34.

30. Sica C, Novara C, Dorz S, Sanavio E. Coping strategies: Evidence for Cross-culture Differences? A preliminary study with the Italian version of Coping Orientations to Problems Experiences (COPE). Pers Individ Dif 1997; 23: 1025-1029.

31. Carver CS. You want to measure coping but your protocol's too long: Consider the brief COPE. Int J Behav Med 1997; 4: 92-100.

32. Carver CS, Scheier MF, Weintraub JK. Assessing coping strategies: a theoretically based approach. J Pers Soc Psychol 1989; 56: 267-283.

33. Grande G, Jordan J, Kummel M, et al. Evaluation of the German type D scale (DS14) and the prevalence of the type D personality pattern in cardiological and psychosomatic patients and healthy subjects. Psychother Psychiatr Med 2004; 54: 413-422.

34. Pedersen SS, Denollet J. Validity of Type D personality construct in Danish post-MI patients and healthy controls. J Psychosom Res 2004; 57: 265-272.

35. Habra ME, Linden W, Anderson JC, Weinberg J. Type D personality is related to cardiovascular and neuroendocrine reactivity to acute stress. $J$ Psychosom Res 2003; 55: 235-245.

36. Clark AM, Whelan HK, Barbour R, MacIntyre PD. A realist study of the mechanisms of cardiac rehabilitation. $J$ Adv Nurs 2005; 52: 362-371.

37. Manuel GM, Roth S, Keefe FJ, Brantley BA. Coping with cancer. J Human Stress 1987; 13: 149-158.

38. Lazarus, R. S, \& Folkman, S. Stress, appraisal and coping. New York: Springer, 1984.

39. Bolger. N. Coping as a personality process: A prospective study. J Pers Soc Psychol 1990; 59: 525-537.

40. McCrae RR, Costa PT Jr. Personality, coping, and coping effectiveness in an adult sample. J Pers 1986; 54 : 385-405. 